\title{
Voltammetric studies of some azo compounds derived from 4-methyl- 6,7-dihydroxy coumarin in microemulsion and aqueous media
}

\author{
Omar A. Hazazi ${ }^{1}$, Refat. El-Sayed ${ }^{\star 1,2}$ and El-Sayed. M. Mabrouk ${ }^{1,2}$
}

${ }^{1}$ Chemistry Department, College of Applied Sciences,Umm Al-Qura University, 21955 Makkah, Saudi Arabia

${ }^{2}$ Chemistry Department, Faculty of Sciences, Benha University, Benha, Egypt

$$
\text { oahazazi@hotmail.com, ref_at@hotmail.com, drsayedmabrouk@yahoo.com }
$$

\begin{abstract}
The cyclic voltammetric (CV) behavior of some azo compounds based on coumarin derivatives was investigated in microemulsion systems and in aqueous solutions. The obtained results indicated that these compounds undergo an irreversible 4-electron reduction step leading to cleavage of the $\mathrm{N}=\mathrm{N}$ center with the formation of amine compounds in all media. The effect of medium on the CV parameters was discussed. The total number of electrons involved in the reduction process was determined by controlled potential coulometry. Also, The effect of substituents on the electrode reaction pathway and the kinetic parameters of the electrode process were calculated and discussed. Based on the data obtained the electroreduction mechanism was suggested and discussed.
\end{abstract}

Key words: Coumarin; Microemulsion; Cyclic voltammetry.

\section{Council for Innovative Research}

\author{
Peer Review Research Publishing System
}

\section{Journal: Journal of Advances in Chemistry}

Vol. 7 , No. 1 


\section{Introduction}

Many coumarins and their derivatives represent one of the most active classes of compounds possessing a wide spectrum of biological activity. Many of these compounds have proven to be active as antibacterial, antifungal, antiinflammatory, anticoagulant, anti-HIV and antitumor agents [1-4]. Coumarins are widely used as additives in food, perfumes, cosmetics, pharmaceuticals and optical brighteners and would dispersed fluorescent and laser dyes [5]. The pharmacological and biochemical properties and therapeutic applications of simple coumarins depend upon the pattern of substitution. Coumarins have attracted intense interest in recent years because of their diverse pharmacological properties [6]. On the other hand, azo dyes are the largest and the most popular group of dyes showing the full palette of colours. Azo dyes compounds are containing $-\mathrm{N}=\mathrm{N}-$ group as a characteristic chromophore, and mainly obtained in diazotization and coupling reaction. As per literature survey, it was found that azo dyes have been most widely used in different application fields, such as dying textile fibres, biomedical studies and advanced in organic synthesis as well as show variety of interesting biological activities including antibacterial and pesticide activities [7]. Recently it was found that coumarin dyes are used in optical recording medium. Coumarin dyes at low concentrations in lubricating oils intended for use in hydraulic fluids or coolants are extremely well suited for indicating or detecting leaks in hydraulic and cooling systems by coupling with one or more nucleophiles [8,9].

Although polarographic and voltammetric studies of azo compounds are frequently carried out [10-13], little attention was paid to azo compounds derived from coumarin derivatives. Recently, several studies were carried out on the electrochemical behavior of azo compounds using different techniques [14-15].

The present paper describes the electrochemical behavior of some coumarin azo dyes in microemulsion and aqueous media using the DP-polarography and cyclic voltammetry techniques. This study brings a contribution to our previous studies [16-19], and other works on the electrochemistry of azo compounds to elucidate the effect of medium and the electrode reduction mechanism.

\section{Experimental}

\subsection{Materials}

Cetyltrimethylammonium bromide (CTAB), sodium dodecyl sulphate (SDS) and n-octane were obtained from Sigma chemicals. Triton X-100 was obtained from Rohem and Haos. CTAB, SDS and Triton X-100 were used as cationic, anionic and nonionic surfactants, respectively. The hydrocarbon n-octane was used as the oil. Sodium bromide and the cosurfactant n-butanol were obtained from Fisher and were used as the electrolyte and the cosolvent, respectively. All solutions were prepared using deionized water to avoid any inorganic or organic impurities. Microemulation were formulated by sequentially adding, surfactant, salt, cosurfactant, hydrocarbon and finally water. However, changing the above sequence does not alter the phase behavior or the properties of microemulsions. The compounds were weighted with accuracy exceeding $\pm 0.02 \mathrm{mg}$. After adding all compounds, the solutions were mixed with Vortex mixer for 30 min or up to complete dissolutions, heated up to $\sim 60^{\circ} \mathrm{C}$ and then ultrasonicated for at least 30 min to sure of homogeneity of sample. All samples were equilibrated in a thermostated room overnight at $22{ }^{\circ} \mathrm{C}$. The exact composition used in these investigations has given in Table (1).

Table (1): Composition of microemulsion system.

\begin{tabular}{lcccc}
\hline \multicolumn{1}{c}{ System } & Surfactant & $\begin{array}{c}\text { Cosurfactant } \\
\text { (n-butanol) }\end{array}$ & $\begin{array}{c}\text { Oil } \\
\text { (n-octane) }\end{array}$ & $\begin{array}{c}\text { Electrolyte } \\
\mathrm{NaBr}\end{array}$ \\
\hline CTAB microemulsion & $5 \%$ & $7.5 \%$ & $3.2 \%$ & $0.1 \mathrm{M}$ \\
Triton X-100 & $5 \%$ & $7.5 \%$ & $3.2 \%$ & $0.1 \mathrm{M}$ \\
SDS microemulsion & $5 \%$ & $7.5 \%$ & $3.2 \%$ & $0.1 \mathrm{M}$ \\
\hline
\end{tabular}

\subsection{Preparation of 4-methyl-6,7-dihydroxy coumarin}

The method of preparation involves preparation of hydroxyquinone triacetate which is subsequently used for preparing 4-methyl-6,7-dihydroxy coumarin according to literature [20]. To preparing the required compounds, an ice solution of hydroxy hydroquinone $(114 \mathrm{~g})$ in ethylacetoacetate $(60 \mathrm{~g})$, concentrated sulfuric acid $(450 \mathrm{ml}$ of $75 \%)$ is added gradually in an hour with stirring at zero temperature. A deep red viscous product is obtained which is kept refrigerated overnight, then poured on an excess of icy water with vigorous stirring. The resulting solid is filtered off, washed several times with distilled water, dried and then recrystallized from ethanol as yellow needles.

\subsection{Preparation of azo dyes derived from 4-methyl-6,7-dihydroxy coumarin}

A solution of $0.01 \mathrm{M}$ of aniline and aniline derivatives $\left(\mathrm{p}-\mathrm{COOH}, \mathrm{p}-\mathrm{OCH}_{3}\right)$ was prepared by dissolving the appropriate amount in $\mathrm{HCl}(1: 1)$, then cooled to $0^{\circ} \mathrm{C}$. At the same time, $0.01 \mathrm{M}$ of sodium nitrite was prepared and kept cooled at $-5{ }^{\circ} \mathrm{C}$. The cold nitrite solution was gradually added to the amine solution with stirring. The reaction mixture was stirred in an ice bath for $20 \mathrm{~min}$ at $-5{ }^{\circ} \mathrm{C}$. The diazonium salt formed was gradually added with vigorous stirring to the appropriate amount of coupler. The coupler used is 4-methyl-6,7-dihydroxy coumarin dissolved in $10 \%$ sodium hydroxide solution and kept at $0{ }^{\circ} \mathrm{C}$. The reaction mixture was kept stirred at $0{ }^{\circ} \mathrm{C}$ for $30 \mathrm{~min}$. The acidity of the reaction mixture was then adjusted at $\mathrm{pH} 6.0$ by carful addition of sodium hydroxide or sodium acetate. The precipitated azo compound was then filtered off, washed with bidistilled water and dried. The purity of the material was ascertained by crystallization and 
constancy of the melting point. The general formula of these compounds was characterized by elemental analysis, IR and ${ }^{1}$ HNMR spectra.<smiles>[X]c1ccc(/N=N/c2c(O)c(O)cc3c(C)cc(=O)oc23)cc1</smiles>
la, $\mathrm{X}=\mathrm{H}$,
$\mathrm{lb}, \mathrm{X}=\mathrm{p}-\mathrm{COOH}$,
Ic, $\mathrm{X}=\mathrm{p}-\mathrm{OCH}_{3}$

\subsection{Instrumentation}

The electrochemical experiments were performed using two electrochemical equipments. The first equipment is an electrochemical analyzer model BAS-100. Experiments were performed in a typical three-component cell. A glassy carbon electrode (GC) of area $0.067 \mathrm{~cm}^{2}$ from BAS was used as the working electrode. A platinum wire of area $1 \mathrm{~cm}^{2}$ was used as the counter electrode. A saturated calomel electrode (SCE) was used as the reference electrode. The second electrochemical equipment used is an polarographic analyzer model 264 A (PARC) from EG \& $G$ and the electrode assembly model $303 \mathrm{~A}$ with a hanging mercury drop electrode (HMDE) of area $2.61 \times 10^{-2} \mathrm{~cm}^{2}$ as a working electrode, $\mathrm{Ag} / \mathrm{AgCl}$ as a reference electrode and a Pt wire as a counter electrode. An X-Y recorder model RE 0089 (Housten Instrument division-PARC) was used for recording the voltammograms and the DP-polarograms. Controlled potential coulometry system (CPC) model 380 (PARC) from EG \& G was used for determination the total number of electrons involved in the reduction process. The $\mathrm{pH}$ of the buffer solutions was checked by using a digital $\mathrm{pH}$-meter model 201 accurate to $\pm 0.05 \mathrm{pH}$ units.

\section{Results and Discussion}

\subsection{Electrochemical behavior of 8-(phenylazo)-6,7-dihydroxy-4-methyl microemulsion and pure aqueous solutions}

\subsubsection{Measurements at glassy carbon electrode (GCE)}

Cyclic voltammograms of $2 \times 10^{-4} \mathrm{M}$ of azo compounds $\left(\mathrm{I}_{\mathrm{a}}\right)$ as a typical example of these compounds were recorded in three different microemulsion systems containing CTAB, SDS and Triton X-100 as model surfactants and in pure aqueous solution. A well-defind single cathodic peak was observed in all media as represented in Fig. (1). No oxidation peaks were observed in the reverse scan which indicated the irreversibility of the reduction process.

Since the coumarin azo dyes which containing hetero ring nucleus is slightly soluble in pure aqueous media and its solubility is not more than $8 \times 10^{-5} \mathrm{M}$ in pure aqueous containing $0.1 \mathrm{M} \mathrm{NaBr}$, therefore, the voltammograms of azo dyes $\left(\mathrm{I}_{\mathrm{a}}\right)$ at this concentration in pure aqueous solutions containing $0.1 \mathrm{M} \mathrm{NaBr}$ supporting electrolyte was studied and showed also a single reduction step, (Fig.1). The voltammograms recorded at different sweep rates from 20 to $500 \mathrm{mV} / \mathrm{s}$ are essentially similar and showed one cathodic peak in the cathodic scan. No peaks were observed in the reverse scan indicating the irreversibility of the reduction process.
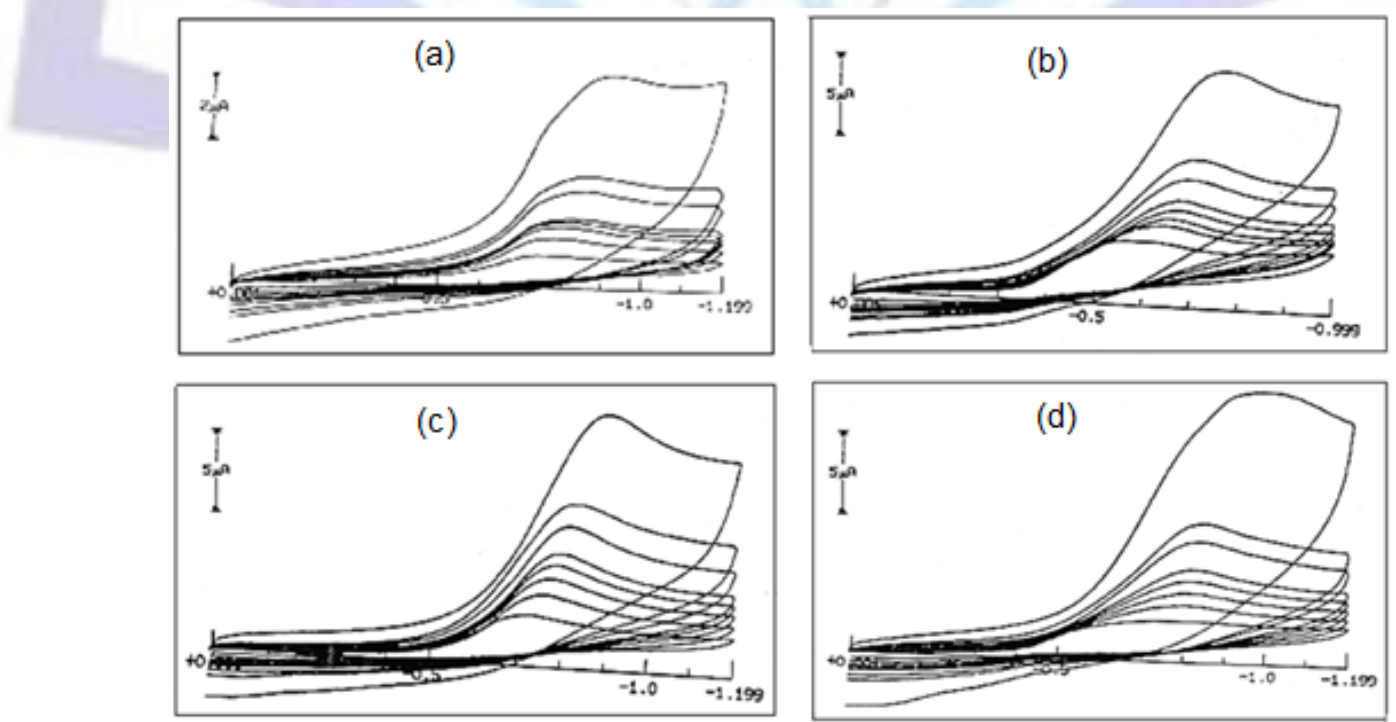

Fig.1: Cyclic voltammograms of coumarin $\left(\mathrm{I}_{\mathrm{a}}\right)$ in microemulsion and aqueous systems containing different surfactants (a) Aqueous (b) CTAB (c)Triton X-100 (d) SDS. The sweep rates are 20, 40, 60, 80, 100, 150, 200 and $500 \mathrm{mV} / \mathrm{sec}$. 
On comparing the peak current $\left(i_{p}\right)$ of coumarin azo dyes $\left(\mathrm{l}_{\mathrm{a}}\right)$ in CTAB, SDS and Triton X-100 microemulsion and in pure aqueous solution, it is clear that the peak current is slightly different from one system to another depending on the size and charge of the microemulsion droplet. On the other hand, the peak current in pure aqueous solution is about one third that in microemulsion media. Table (2). The peak potential $\left(E_{p}\right)$ displayed a cathodic shift on increasing the sweep rate $(v)$ which confirmed the irreversibility of the electrode process [21]. It was found that the reduction process takes place at less negative potentials in CTAB system compared to Triton X-100 and SDS, depending on the effect of electrostatic interaction and stabilization effects of surfactants on different entities formed in solution during the electrochemical process.

Table (2): Cyclic voltammetric data obtained for $0.2 \mathrm{mM}$ of coumarin azo compound (la) in different media.

\begin{tabular}{|c|c|c|c|c|c|c|c|}
\hline \multirow{2}{*}{ System } & \multirow{2}{*}{ Sweep rate } & \multirow{2}{*}{$I_{p, c}$} & \multirow{2}{*}{$\begin{array}{l}-E_{p, c} \\
m V\end{array}$} & \multirow{2}{*}{$\begin{array}{l}\mathrm{dE}_{\mathrm{p}} / \\
\mathrm{dln} v\end{array}$} & \multirow{2}{*}{$\begin{array}{c}\mathrm{D} \times 10^{6} \\
\mathrm{Cm}^{2} / \mathrm{sec}\end{array}$} & \multicolumn{2}{|c|}{$\alpha \mathrm{n}_{\mathrm{a}}$} \\
\hline & & & & & & $\mathrm{n}_{\mathrm{a}}=1.0$ & 2.0 \\
\hline \multirow[t]{5}{*}{ Pure aqueous } & 20 & 0.92 & 744 & & & & \\
\hline & 60 & 1.79 & 767 & & & & \\
\hline & 100 & 2.05 & 792 & 4.9 & 8.16 & 0.26 & 0.13 \\
\hline & 200 & 3.28 & 847 & & & & \\
\hline & 500 & 6.35 & 892 & & & & \\
\hline \multirow[t]{5}{*}{ CTAB } & 20 & 2.93 & 602 & & & & \\
\hline & 60 & 5.29 & 648 & & & & \\
\hline & 100 & 6.47 & 671 & 4.51 & 6.19 & 0.28 & 0.14 \\
\hline & 200 & 9.31 & 696 & & & & \\
\hline & 500 & 15.20 & 747 & & & & \\
\hline \multirow[t]{5}{*}{ SDS } & 20 & 2.67 & 799 & & & & \\
\hline & 60 & 4.56 & 805 & & & & \\
\hline & 100 & 6.08 & 828 & 3.90 & 7.68 & 0.33 & 0.17 \\
\hline & 200 & 9.15 & 846 & & & & \\
\hline & 500 & 17.83 & 928 & & & & \\
\hline \multirow[t]{4}{*}{ Triton X-100 } & 20 & 2.91 & 726 & & & & \\
\hline & 60 & 5.02 & 768 & & & & \\
\hline & 100 & 6.52 & 743 & 4.11 & 5.23 & 0.31 & 0.16 \\
\hline & 500 & 14.58 & 864 & & & & \\
\hline
\end{tabular}

According to Delahy [22] and using equation (1), the plots of the cathodic peak current ( $i_{p c}$ ) versus the square root of the sweep rate $\left(v^{1 / 2}\right)$, linear correlations mostly passing through the origin (Fig. 2a) obtained in case of microemulsion media revealing that the reduction process of azo dyes $\left(\mathrm{I}_{\mathrm{a}}\right)$ is mainly controlled by diffusion, but in pure aqueous solution (Fig. 2b) the straight line obtained deviates from passing through the origin which may be due to adsorption phenomenon of the depolarizer at the electrode surface [23].

$$
i_{p}=3.01 \times 10^{-5} n\left(\alpha n_{a}\right) A D^{1 / 2} C v^{1 / 2}
$$

On employing the relationship (2) that correlates the shift in peak potential with the sweep rate [24], linear correlations are obtained. From the slope values of these plots the transfer coefficient $(\alpha)$ can be calculated. The values of $(\alpha)$ could be calculated for the probable values of $\left(n_{a}\right)$ by considering the number of electrons involved in the rate-determining step $\left(n_{a}\right)$ may be one or two. As shown in Table (1), the most probable values of $(\alpha)$ are obtained at $n_{a}=1.0$. These results indicate that the rate-determining step of the reduction process should involve one electron in all media.

$$
\left.E_{p}=-1.14\left(R T / \alpha n_{a} F\right)+R T / \alpha n_{a} F\right) \ln \left(k_{f, h}^{0} / D^{1 / 2}\right)-\left(R T / 2 \alpha n_{a} F\right) \ln _{a} n_{a} v
$$




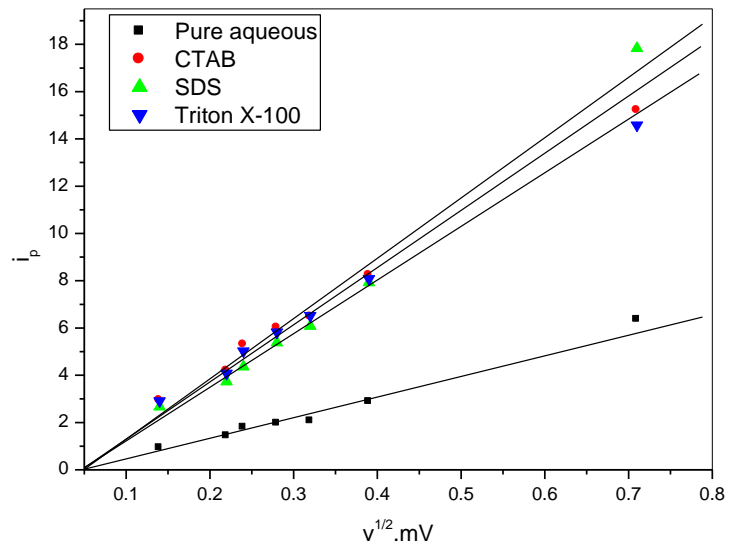

Fig. 2a: $i_{p}-v^{1 / 2}$ plot of azo compound $\left(I_{a}\right)$ in microemulsion media.

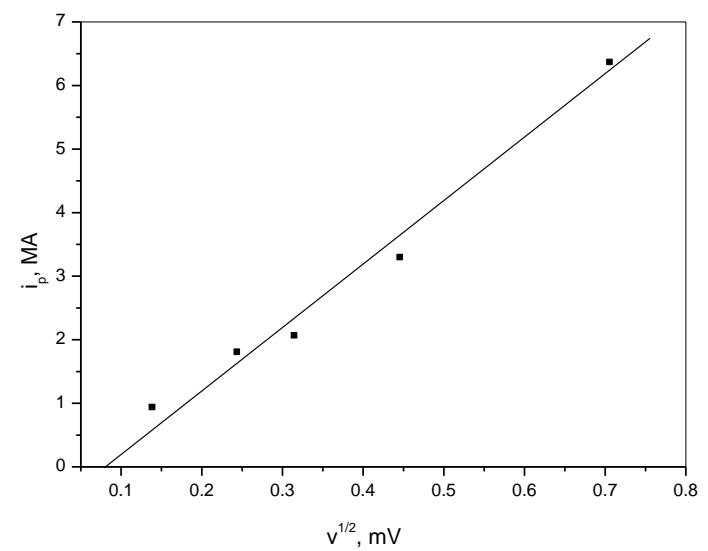

Fig. $2 b: i_{p}-v^{1 / 2}$ plot of azo compound $\left(I_{a}\right)$ in aqueous solution.

\subsubsection{Measurements at hanging dropping mercury electrode (HDME)}

Due to the low solubility of coumarin azo dyes in pure aqueous solutions, the measurements were done in $40 \%$ $(\mathrm{v} / \mathrm{v})$ ethanol. The cyclic voltammograms and DP-polarograms of azo compounds ( $\left.\mathrm{l}_{\mathrm{a}-\mathrm{c}}\right)$ were recorded in Britton-Robinson [25] buffer solutions of $\mathrm{pH}(2-12)$ containing $40 \%(\mathrm{v} / \mathrm{v})$ ethanol. The recorded voltammograms in all $\mathrm{pH}$ values showed only a single reduction wave for all the compounds under investigation as in case of the measurements at the GCE. No oxidation peaks were observed in the reverse scan which indicates the irreversibility of reduction process,(Fig.3).

The peak current $\left(\mathrm{i}_{\mathrm{pc}}\right)$ decreases slightly on increasing the $\mathrm{pH}$ of the solution which may be due to the viscosity change of the electrolysis medium. Using the relation (1) that correlates the peak current and the square root of sweep rate and on plotting $\mathrm{E}_{\mathrm{p}}$ vs $\mathrm{v}^{1 / 2}$ at different $\mathrm{pH}$ values, linear correlations not passing through the origin and intersecting the negative part of the peak current axis are obtained, (Fig. 4), indicating some adsorption contribution to the electrode process. This behavior is not similar to that obtained in case of microemulsion media in which the obtained linear correlations pass through the origin.

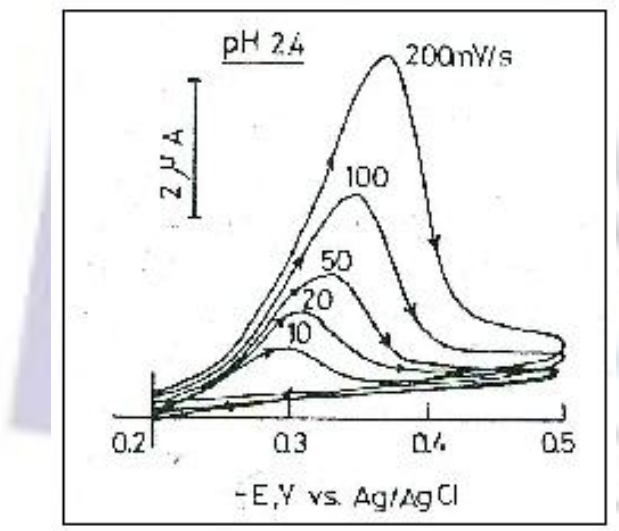

Fig. 3: Cyclic voltammogram of $1 \times 10^{-4} \mathrm{M}$ of azo compound (la) in aqueous buffer solution (pH.2.4)at different scan rates at HMDE
Fig. 4: $i_{p}-v^{1 / 2}$ plot of azo compound $\left(I_{a}\right)$ in pure aqueous solutions.

The effect of sweep rate on the reduction peak revealed that on increasing the sweep rate, the peak potential shifted to more negative values which is further indication on the irreversibility of the electrode process. On employing the relationship (2) that correlates the peak potential $\left(E_{p c}\right)$ and the sweep rate $(v)$ and on plotting $E_{p c}$ vs. Inv, linear correlations are obtained. The transfer coefficient $(\alpha)$ values were determined from the slope values of these linear plots at the probable values of $\left(n_{a}\right)$. The data given in Table (3) revealed that $\alpha$ values are obtained at $n_{a}$ equal to 1.0. Thus, the ratedetermining step of the electrode reaction should also involve one electron as in case of microemulsion media. 
Table (3): Cyclic voltammetric data obtained for coumarin azo compounds (I) in aqueous buffer solutions of different $\mathrm{pH}$ values.

\begin{tabular}{|c|c|c|c|c|c|c|}
\hline \multirow{2}{*}{ Compd. } & \multirow{2}{*}{$\mathrm{pH}$} & \multirow{2}{*}{$\begin{array}{l}\mathrm{dE}_{\mathrm{p}} / \\
\text { dlno }\end{array}$} & \multicolumn{2}{|c|}{$\alpha n_{a}$} & \multirow{2}{*}{$\begin{array}{c}\mathrm{k}_{\mathrm{f}, \mathrm{h}}^{0} \\
\mathrm{~cm} / \mathrm{sec}\end{array}$} & \multirow{2}{*}{$\begin{array}{c}\Delta \mathrm{G}^{*} \\
\mathrm{KJ} / \mathrm{mol}\end{array}$} \\
\hline & & & 1.0 & 2.0 & & \\
\hline \multirow[t]{3}{*}{ la } & 2.4 & 0.033 & 0.39 & 0.20 & $1.85 \times 10^{-4}$ & 213.3 \\
\hline & 7.0 & 0.025 & 0.51 & 0.26 & $1.58 \times 10^{-7}$ & 287.3 \\
\hline & 9.2 & 0.020 & 0.63 & 0.32 & $1.00 \times 10^{-9}$ & 336.7 \\
\hline \multirow[t]{3}{*}{$\mathrm{Ib}$} & 2.2 & 0.032 & 0.40 & 0.20 & $1.05 \times 10^{-4}$ & 214.3 \\
\hline & 7.0 & 0.026 & 0.49 & 0.25 & $3.24 \times 10^{-7}$ & 279.8 \\
\hline & 9.3 & 0.018 & 0.69 & 0.35 & $4.93 \times 10^{-10}$ & 347.9 \\
\hline \multirow[t]{3}{*}{ IC } & 2.3 & 0.026 & 0.50 & 0.25 & $6.06 \times 10^{-6}$ & 249.2 \\
\hline & 7.1 & 0.023 & 0.57 & 0.28 & $4.00 \times 10^{-9}$ & 323.8 \\
\hline & 9.2 & 0.019 & 0.67 & 0.34 & $1.36 \times 10^{-10}$ & 361.4 \\
\hline
\end{tabular}

The DP-polarograms of the azo compounds under investigation showed a single cathodic peak in all buffer solutions,(Fig.5). A cathodic shift in peak potential is observed on increasing the $\mathrm{pH}$ of the solution denoting that hydrogen ions are consumed in the reduction process [26].On plotting $E_{p}$ vs the $\mathrm{pH}$ of solution, linear correlations are obtained, Fig.(6), indicating that only one mechanism is operating at all $\mathrm{pH}$ values. The slope values of these plots ranging from 66$86 \mathrm{mV}$. The number of protons $\left(\mathrm{Z}^{+}\right)$involved in the rate- determining step was determined using the following relationship [27]:

$$
\mathrm{Z}_{\mathrm{H}}^{+}=\left(\Delta \mathrm{E}_{\mathrm{p}} / \Delta \mathrm{pH}\right) /\left(0.0591 / \alpha \mathrm{n}_{\mathrm{a}}\right)=\mathrm{S}_{2} / \mathrm{S}_{1}
$$

It was found that $Z_{H}{ }^{+}$equal to 1.0 , which revealing that the rate-determining step of the electrode reaction should involve one electron and one proton.

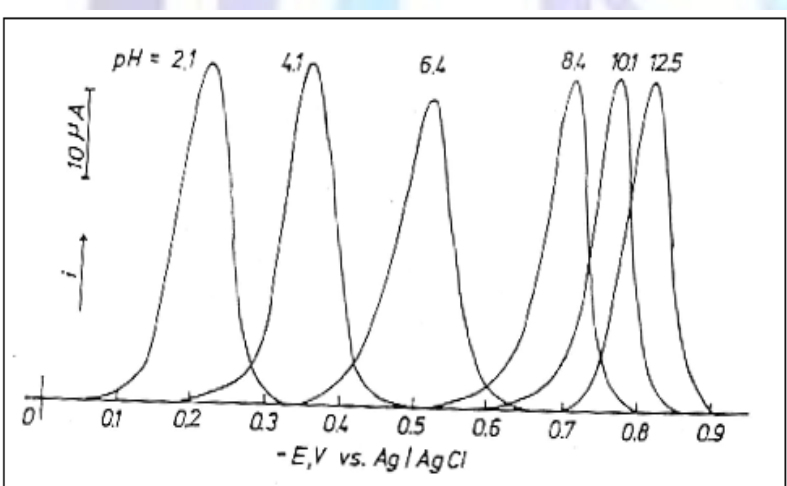

Fig. 5: DP-polarograms of azo compound $\left(I_{a}\right)$ at different $\mathrm{pH}$ values

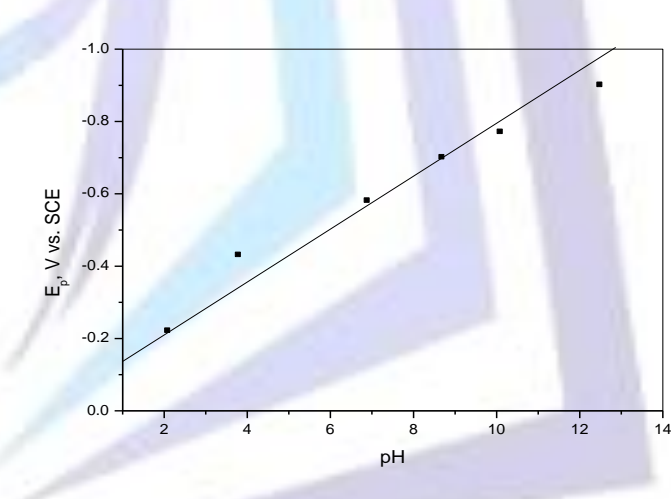

Fig. 6: Ep-pH plot of azo compound $\left(I_{a}\right)$ at different $\mathrm{pH}$ values

\subsection{Controlled potential electrolysis (coulomtry)}

In order to give the electrode reaction mechanism of the coumarinazo dyes in both microemulsion and aqueous media, the total number of electrons $(n)$ consumed in the reduction process should be obtained. Controlled potential electrolysis was used for this purpose. The experiment was applied using $1 \times 10^{-4} \mathrm{M}$ of each azo compound in the three microemulsion media and in aqueous solutions of $\mathrm{pH} \mathrm{2,7}$ and 9. The electrolysis was performed at a large mercury pool cathode. The negative potential applied during electrolysis is corresponded to the reduction peak value. Applying the Faraday equation $\mathrm{Q}=\mathrm{nFW} / \mathrm{M}$, in which $\mathrm{W}$ is the weight of the dissolved sample in grams, $\mathrm{M}$ is its molecular weight and $\mathrm{F}$ is the Faraday's constant, the average number of electrons consumed in the reduction process in the different media was found to be 4 electrons, which corresponding to the cleavage of $\mathrm{N}=\mathrm{N}$ center to the amine stage. The cleavage of the azo group is confirmed by the disappeared of the $\pi-\pi^{*}$ band characteristic of the $N=N$ which observed at $\lambda_{m}=375 \mathrm{~nm}$.

According to Zuman [26], the sequence of proton and electron additions were proposed to be either, $\mathrm{H}^{+}, \mathrm{e}, \mathrm{H}^{+}, \mathrm{e}$ or $\mathrm{H}^{+}, \mathrm{e}, \mathrm{e}, \mathrm{H}^{+}$. In the light of structural genesis of the compounds under investigation, the later sequence is the most probable. Thus, the operating mechanism of the electrode reaction can be represented by scheme 1. 
<smiles>[X]c1cccc(N=NBr)c1</smiles>

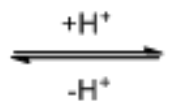<smiles>[X]c1cccc(N=[N+][AlH2])c1</smiles><smiles>[X]c1cccc(N=[N+][Al])c1</smiles><smiles>[X][X]NNc1cccc([X])c1</smiles><smiles>[X]c1cc(NN[Al])ccc1[18O][C-]C</smiles><smiles>[Z17]NNc1cccc([X])c1</smiles><smiles>[X]c1cccc(N)c1</smiles><smiles>Cc1cc(=O)oc2c(C)c(O)c(O)cc12</smiles>

$$
\left(E_{1}=E_{2}=E_{p}\right)
$$

\subsection{Substituent effects}

The peak potential $\left(E_{p}\right)$ values of a related organic compounds depend mainly on the type of substituents in the molecule. Thus, the difference in the $E_{p}$ of the unsubstituted, $E_{p}(H)$, and the substituted benzenoid derivatives, Ep (x) is related to the Hammett substituent constant $\left(\sigma_{x}\right)$ and the reaction constant $\left(\rho_{n, R}\right)$ by the relation [28]:

$$
\Delta E_{p}=\rho_{n}, R \sigma_{x}
$$

In the present study, it was found that compounds substituted by electron-withdrawing group like $\mathrm{p}-\mathrm{Cl}$ reduced at less negative potentials compared to the unsubstituted compound. On the reverse, compounds substituted by electrondonating group like $\mathrm{p}-\mathrm{OCH}_{3}$ is reduced at higher negative potentials. On plotting the peak potential $\left(\mathrm{E}_{\mathrm{p}}\right)$ obtained from DPpolarography of the three azo compounds against the $\sigma_{x}$ values which obtained from the tabulation of Ritchie and Sager [25] at different $\mathrm{pH}$ values, linear correlations are obtained, Fig. (7). These results indicate that compounds containing electron-withdrawing groups like $\mathrm{p}-\mathrm{Cl}$ accelerate the reduction process due to the increased basicity of the unprotonated nitrogen atom linked to the phenyl ring and consequently promotes the reduction of the electroactive $\mathrm{N}=\mathrm{N}$ center. On the other hand, compounds possessing electron-donating groups like $\mathrm{p}-\mathrm{OCH}_{3}$ stabilizes the electronegativity on $\mathrm{N}$-atom attached to the phenyl ring, thus leading to retardation of the reduction process.

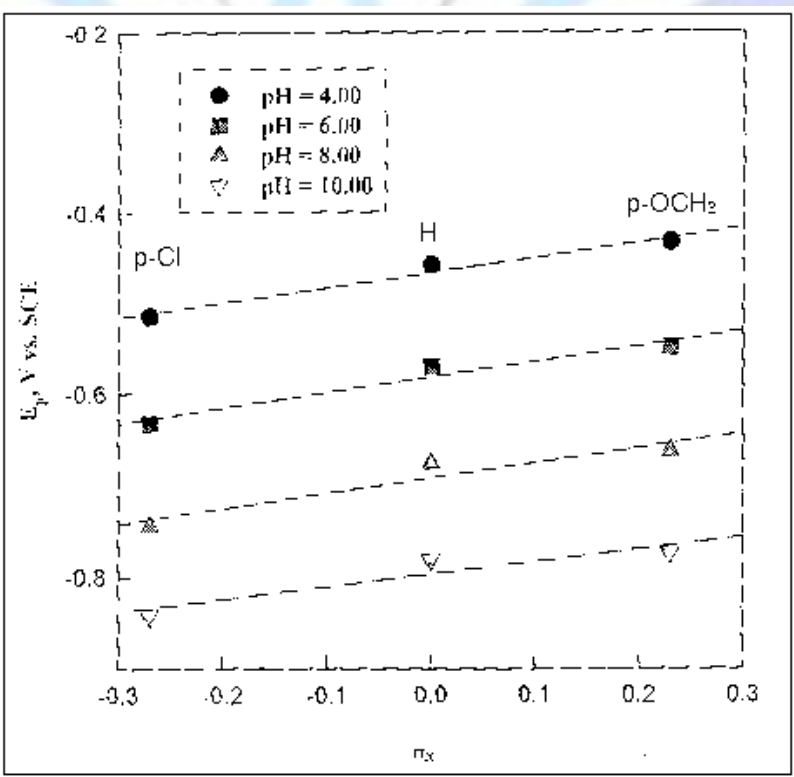

Fig. 7: Ep vs. $\sigma_{x}$ plot of azo compounds $I_{a-c}$ in buffer solutions of different $p H$ values 


\subsection{Kinetic parameters}

The heterogeneous rate constant $\left(\mathrm{k}_{\mathrm{f}, \mathrm{h}}^{0}\right)$ of the electrode reaction of the coumarinazo compound (I) was determined [29] and the energy of activation $\left(\Delta \mathrm{G}^{*}\right)$ was calculated [30]. The diffusion coefficients of the azo compounds in microemulsion and pure aqueous media was calculated using Stock-Einstein equation [31], and given in Table (4). Values of the heterogeneous rate constant were found to be higher in CTAB system than in pure aqueous solution, SDS or Triton $X-100$, Table (4). These results indicated that the electrostatic effect of CTAB increases the electron affinity in the vicinity of the cathodic electrode, which accelerates the cathodic reaction. Also, the higher values of $k_{f, h}^{\circ}$ in microemulsions compared with that of pure aqueous solutions may be due to the complication of the later such as adsorption and catalytic effects which are disappeared in microemulsion systems. On the other hand, the heterogeneous rate constants of coumarin azo dyes determined in aqueous buffer solutions, Table (4), indicate that the rate constant decreases with increasing the $\mathrm{pH}$ value. This behavior revealed that the electrode reaction becomes more difficult and more irreversible on decreasing the protons concentration in the electrolysis solution. Consequently, value of energy of activation of coumarin azo dye la in CTAB was found to be less than that obtained in Triton X-100 or SDS systems. These results indicated that the electrode reaction is more difficult in anionic SDS due to the electrostatic repulsion effect and consequently required higher energy of activation compared to CTAB or the natural Triton X-100. Also, the data given in Table (4) denoted that $\Delta \mathrm{G}^{*}$ increases with increasing the $\mathrm{pH}$ of the electrolysis solution. This behavior could be attributed to the fact that the protonated or neutral molecules existing at lower $\mathrm{pH}$ values are diffused readily to the electrode surface which in turn reduces the values of activation energy compared with the non-protonated forms present in alkaline solutions.

Table (4): Kinetic parameters of coumarinazo compound (la) in pure aqueous and in microemulsion

\section{References}

\begin{tabular}{lcc}
\hline System & $\begin{array}{c}\mathrm{k}_{\mathrm{f}, \mathrm{h}}^{\mathrm{c}} \\
\mathrm{cm} / \mathrm{sec}\end{array}$ & $\begin{array}{c}\Delta \mathrm{G}^{*} \\
\mathrm{KJ} / \mathrm{mol}\end{array}$ \\
\hline Pure aqueous & $3.1 \times 10^{-6}$ & 256.2 \\
CTAB & $1.14 \times 10^{-5}$ & 242.5 \\
SDS & $1.59 \times 10^{-6}$ & 263.2 \\
Triton X-100 & $9.26 \times 10^{-6}$ & 268.9 \\
\hline
\end{tabular}

[1] Kadhum A H, Al-Amiery A A, Musa A Y and Mohamad A B, 2011. Int. J. Mol. Sci. 12(9) 5747.

[2] Venugopala K N, Rashmi V, Odhav B, 2013. Biomed Res Int. Vol. (2013) Article ID 963248. Mar 24.

[3] Rajesh M P and Natvar P, 2011. Journal of Advanced Pharmacy Education \& Research 1, 52.

[4] Kamal El-Dean A M, Zaki R M, Geies A A, Radwan S M and Tolba M S, 2013. Frameworks, Russian Journal of Bioorganic Chemistry, 39 (5), 553.

[5] Zaki R M, Elossaily Y. A and Kamal El-Dean A. M, 2012. Russian Journal of Bioorganic Chemistry, 38 (6), 639.

[6] Kostoval, 2005. Curr. Med. Chem.-Anti-Cancer Agents, 5, 29.

[7] Sudhir K P, Ghosh P, Rout S. K and Paul D, 2013. Rasayan. J. Chem, 6 (2), 147.

[8] Thorat B R, Yamgar R S, Nawathye V V, Dalavi D B, Upadhyaya D J and Gadre A G, 2012. International Journal of Chemical Sciences and Applications, 3(3), 356.

[9] Gopi C, Dhanaraju M D, 2011. Journal of Pharmacy Research, 4 (4), 1037.

[10] Ksson A, Erand N, 1999. Electrochim. Acta, 44, 4029.

[11] Vngureaua E, Razub A C, Birzanb L, Cretua M and Buicaa G, 2008. Electrochim. Acta, 53, 7089.

[12] Menek $N$ and Karaman $Y, 2006$. Dyes and Pigments, 68, 101.

[13] Jain R, Pandmaja P and Gupta S, 1997. Can. J. Chem., 75, 567.

[14] Karaman Y and Menek N, 2012. J. Electrochemical Society, 159 (10), 805.

[15] Sreenivasulu R, Nagaraju V and Ramana P. V, 2013. International Journal of Research and Pharmaceutical and Biomedical Science, 4(4), 1153.

[16] Killa H M, Mabrouk E M, Abd El-Fattah A A and Yasen S A, 1991. Analytical Letters, 24, 275.

[17] Mabrouk E. M, Ghoneim M M, Issa Y M and Hassamein A M, 1993. Egypt. J. Chem. 36, 225.

[18] Mabrouk E M, KillaH M, Abd El-Fattah A. A and Yasen S A, 1992. Collect. Czech. Chem. Communication, 57, 268. 
[19] El-Sayed R, Mohamed A. A and Mabrouk E .M, 2010. Material Science Research, 7(2),339

[20] Katayal M and Singh H. B, 1968. Talanta, 15, 1046.

[21] Nichlson R S and Shain I. 1976. Anal. Chem. 36, 706.

[22] Delahy P." New Instrumental Methods in Electrochemistry". Interscience Publishers, Inc., New York, 1953.

[23] Bard A J and Faulkner L R, 1980. Electrochemical Methods Fundemtal and Applications, John Wiley, New York 218.

[24] Galus Z, 1976. Fundamental of Electrochemical Analysis, Ellis Horwood, Chichester,. Chapter 7.

[25] Britton H T S." Hydrogen lons", 4th Ed. Chapmann and Hall, 1952.

[26] Zuman P, 1969. The Elucidation of Organic Elctrode Processes, Academic Press, 115.

[27] Meites L, 1955. Polarographic Techniques, Interscience Publishers, Inc, New, York, 24.

[28] Ritchi C D and Sager W. F, 1964. Progress in physical Organic Chemistry, Vol.2, Interscience Publisher, Inc. 334.

[29] Klinger R J and Kochi J K, 1981. J. Phy. Chem, 85, 1731.

[30] Heyrovesky J, 1941. Polarographie, Springer Veloge (1941) 105.

[31] Einstien A, 1906. Ann. Phys., 19, 289. 